\title{
The Effects for Extracellular Polymeric Sustances of Cladophora glomerata under Different Culture pH and Salinities
}

\author{
Yi-Chao Lee, Hwey-Lin Sheu, Shui-Ping Chang* \\ Department of Environmental Engineering, Kun Shan University, Tainan City, Taiwan. \\ * Corresponding author. Tel.: +886-6-2055011; email: spchang@mail.ksu.edu.tw \\ Manuscript submitted September 10, 2018; accepted March 23, 2019. \\ doi: 10.17706/ijbbb.2019.9.3.150-157
}

\begin{abstract}
The extracellular polymeric sustances (EPS) of algae have been studied as high-value natural resources for a number of application. Cladophora glomerata is the most abundant algae in freshwater throughout the world. This study discovered that under algal favoured $\mathrm{pH}$ environment, changing culture salinity can induce C. glomerata to secrete massive amount of EPS. Under $\mathrm{pH} 7.0$ and $\mathrm{pH} 8.0$, the total EPS increased from $3.10 \mathrm{mg} \mathrm{g}^{-1}$ fresh algae to $6.47 \mathrm{mg} \mathrm{g}^{-1}$ fresh algae, the protein to polysaccharide ratio (P/S) decreased from 0.31 to 0.21 with the increase in the salinity from $0 \%$ to $30.0 \%$. For pH 5.0, 6.0 and pH 9.0, 10.0 culture conditions, the total EPS between $1.17 \mathrm{mg} \mathrm{g}^{-1}$ fresh algae to $4.32 \mathrm{mg} \mathrm{g}^{-1}$ fresh algae, the P/S ratio between 0.24 to 0.29 with the increase in the salinity from $0 \%$ to $30.0 \%$. Therefore, the total EPS and P/S ratio are influenced by culture salinity and $\mathrm{pH}$ obviously.
\end{abstract}

Key words: Cladophora glomerata, extracellular polymeric substances (EPS), protein, polysaccharide, salinity, $\mathrm{pH}$.

\section{Introduction}

Algae can excrete various EPS into their immediate living environment during their life cycle. These algal EPS mainly consist of polysaccharides, proteins, nucleic acid and lipid [1]-[4]. EPS are an abundant source of structurally and compositionally diverse biopolymers.

In recent years, EPS have been studied and used as renewable natural resources for wide spectrum of application, including food, pharmaceuticals/cosmetics, nutraceuticals, and so no [5]-[7]. Therefore, making the in-depth study of EPS is also important in term of development of value-added EPS applications [8]-[11]. Algal is the photosynthetic organism can grow in the different environment and EPS production which makes algae a perfect candidate for biotechnological exploration [12]-[14].

As recent research has shown, the EPS of the algae is highly sensitive to salinity [15]. Once the salinity of the growing environment is increased, the species of $C$. glomerata starts to change the composition of polysaccharide and protein in EPS.

Bellis (1968) found that cultures of C. glomerata were killed at initial pH values less than 7.0 and above 10.0. At initial $\mathrm{pH}$ values immediately adjacent to these limits the cultures produced only akinetes, but branched filaments developed where initial $\mathrm{pH}$ values ranged from 7.25-9.01 [16]. However, the changes of algal secretions (EPS) with $\mathrm{pH}$ changes are unknown.

Cladophora glomerata (Chlorophyta, Cladophoraceae) is widely distributed around the world and receive 
a significant amount of attention from biologists. Wen et al. (2007) [17] investigated these types of green algae in rivers in southern Taiwan and measured that the biomass of these algae reached up to $117 \mathrm{~g} / \mathrm{m}^{2}$. Surveys of the Great Lakes further found green algae biomass to be as great as $940 \mathrm{~g} / \mathrm{m}^{2}$ [18]. These macrobenthic algae up take nutrients from the water. They tential to be developed as biological materials.

This study investigated EPS production under different salinity and $\mathrm{pH}$ by exploring the features of $C$. glomerata. This study also investigated the changes of polysaccharides and proteins, and protein to polysaccharide ratio $(\mathrm{P} / \mathrm{S})$.

\section{Materials and Methods}

\subsection{Algae}

Cladophora is a branched and filamentous algae, the cell walls of which comprise an inner layer of cellulose, a middle layer of pectin, and an outer layer of chitin. In fresh water. The surface of the algae is rougher, hosting a number of epiphytes, primarily Bacillariophyta as well as Cladophora, Cyanophyta, and Euglenophyta. C. glomerata usually is the dominant species in its habitat. In this study, the species $C$. glomerata was collected from a main river in southern Taiwan, the upstream of the Zengwun River $\left(23^{\circ} 04^{\prime} \mathrm{N}\right.$, $120^{\circ} 04^{\prime} \mathrm{E}$ ), and then transferred to aquariums with different salinities and $\mathrm{pH}$ for further culturing.

\subsection{Influence of Salinity and pH on C. glomerata EPS}

The sessile C. glomerata grew healthily on the carriers (pebbles) and was harvested from the upstream of the Zengwun River in southern Taiwan. The river water above the tidal river reaches was also brought back to the laboratory to prepare a culture medium with different concentrations of salinity, including 5 different salinities such as unadjusted (assuming it was $0.0 \%$ ), 3.0\%, 10.0\%, 20.0\%, and 30.0\%o. C.glomerata was cultured in an outdoor open system without $\mathrm{CO}_{2}$ addition and the culture presented a $\mathrm{pH}$ values naturally ranging from 6.2-8.1. therefore to test the influence of $\mathrm{pH}$ on EPS production under different salinities. six $\mathrm{pH}$ values $\left(5.0,6.0,7.0,8.0,9.0\right.$ and 10.0) were tested after adjustment using $1.0 \mathrm{~mol} / \mathrm{L} \mathrm{HNO}_{3}$ or $1.0 \mathrm{~mol} / \mathrm{L}$ $\mathrm{NaOH}$ solution. Individual aquariums contained 10 liters of river water with different salinities, and the water was circulated using a small motor to create an adequate environment in which to culture $C$. glomerata. Samples were then taken at $48 \mathrm{~h}$ after treated.

\subsection{Thickness of Extracellular Mucilage Layer}

To measure the mucilage layer to determine the EPS, we employed the methods used by Tien et al. (2002) [9] and Chiou et al. (2010) [10]. Fig. 1 shows measurements of the mucilage layer of the algae. Algae samples were placed on glass slides with an appropriate quantity of India ink and then observed using an optical microscope. The green regions in the image are the cell walls of $C$. glomerata; the uniform halo on the outside was used to estimate the thickness of the mucilage layer.

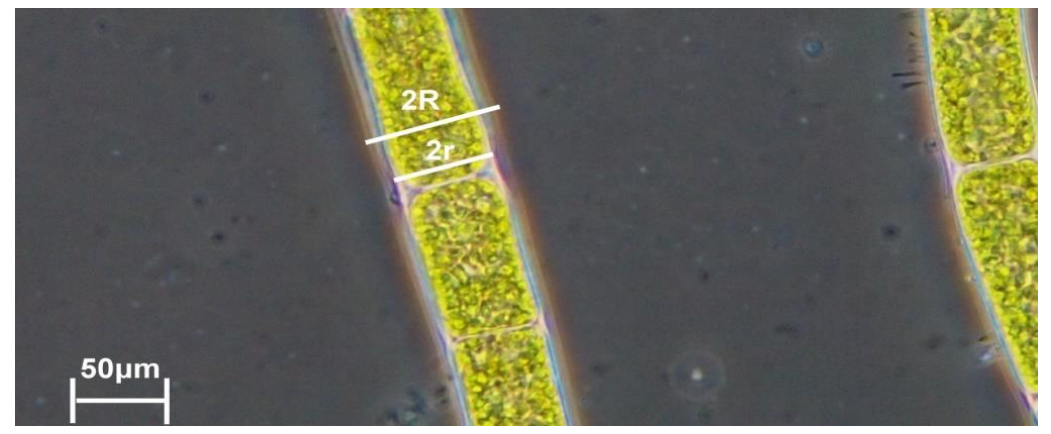

Fig. 1. Illustration of how the measurement of mucilage layer (the thickness of mucilage layer=R-r, scale

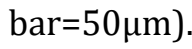




\subsection{EPS Extraction and Analysis}

The ultrasonication method was used for the EPS extraction [12], [19]-[21]. The algae was harvested from the aquarium, washed twice with tap water, and drained in a strainer at room temperature for $2 \mathrm{~h}$ until it dried naturally. Afterward extraction procedures were started (as indicated in Fig. 2). All chemicals used in this work were of analytical grade. Polysaccharide content was determined by the phenol-sulfuric acid using glucose as a standard [22]. Protein content was determined according to Bradford (1976) with bovine serum albumin BSA, Sigma A2153 100mg/ml [23]. The total EPS content was measured as the sum of these two substances [24], [25]. All sample measurements were 6 repeated.

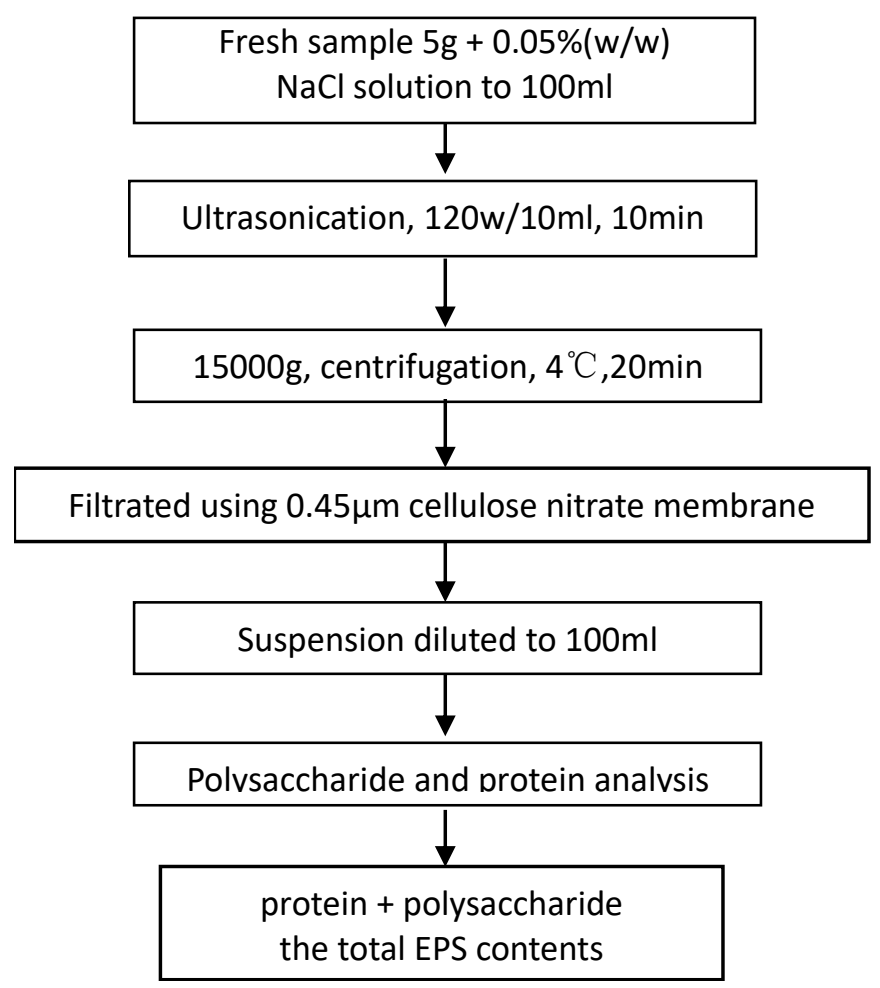

Fig. 2. Procedure for the EPS extraction process for $C$. glomera.

\section{Results and Discussion}

\subsection{The Influence of Salinity and pH on the C. glomerata Mucilage Layer}

To determine the influence of variations in salinity and $\mathrm{pH}$ on the EPS and epiphytes of C. glomerata, we conducted experiments using onsite river water and various concentrations of $\mathrm{NaCl},(0.0 \%, 3.0 \%, 5.0 \%$, $10.0 \%$ o, 20.0\% and 30.0\%o salinity) under six different $\mathrm{pH}$ values to cultivate well-grown Cladophora algae samples.

Table 1 and Fig. 3 demonstrate the changes of mucilage layer thickness under different culture conditions with different salinities and $\mathrm{pH}$ values. Under $\mathrm{pH} 7.0$ and pH8.0, the results indicated that the culture salinity increased ( $\geqq 3.0 \% 0$ ), EPS secretion also greatly increased accordingly. In this case, C. glomerata, which grows naturally and favourable $\mathrm{pH}$ conditions in freshwater areas and thus hardly forms a mucilage layer outside of its cell walls, may start to formulate mucilage layers in accordance with the increase in salinity. To protect itself, the algae could change its physiological conditions to adapt to the environmental changes. But the study results implied that critical salinity for creating significant changes in EPS production was $3.0 \%$. Under the $\mathrm{pH}$ value $(5.0,6.0,9.0,10.0)$, C. glomerata decreased the influence of algal 
secretion with the changes of salinites. In the culture experiments, C. glomerata became colourless within $48 \mathrm{~h}$ after being placed in a pH 5.0 and pH10.0 culture conditions.

Table 1. Changes of the Thickness of Mucilage Layer in Different pH and Salinity

\begin{tabular}{ccccccc}
\hline \multirow{2}{*}{ salinity } & \multicolumn{7}{c}{$\mathrm{pH}$} \\
\cline { 2 - 7 } $1(0.0 \% 0)$ & 5.0 & 6.0 & 7.0 & 8.0 & 9.0 & 10.0 \\
\cline { 2 - 7 } $2(3.0 \% 0)$ & $0.75 \pm 0.02$ & $2.20 \pm 0.04$ & $2.39 \pm 0.04$ & $2.46 \pm 0.04$ & $2.51 \pm 0.04$ & $1.00 \pm 0.04$ \\
$3(10.0 \% 0)$ & $0.87 \pm 0.03$ & $3.26 \pm 0.07$ & $4.45 \pm 0.08$ & $4.79 \pm 0.09$ & $3.21 \pm 0.10$ & $1.37 \pm 0.09$ \\
$4(20.0 \% 0)$ & $0.87 \pm 0.03$ & $3.31 \pm 0.07$ & $4.70 \pm 0.08$ & $5.20 \pm 0.09$ & $3.32 \pm 0.09$ & $1.42 \pm 0.09$ \\
$5(30.0 \% 0)$ & $0.91 \pm 0.05$ & $3.45 \pm 0.10$ & $5.22 \pm 0.11$ & $5.51 \pm 0.12$ & $3.40 \pm 0.13$ & $1.49 \pm 0.12$ \\
\hline \multicolumn{7}{c}{} \\
\hline \hline
\end{tabular}

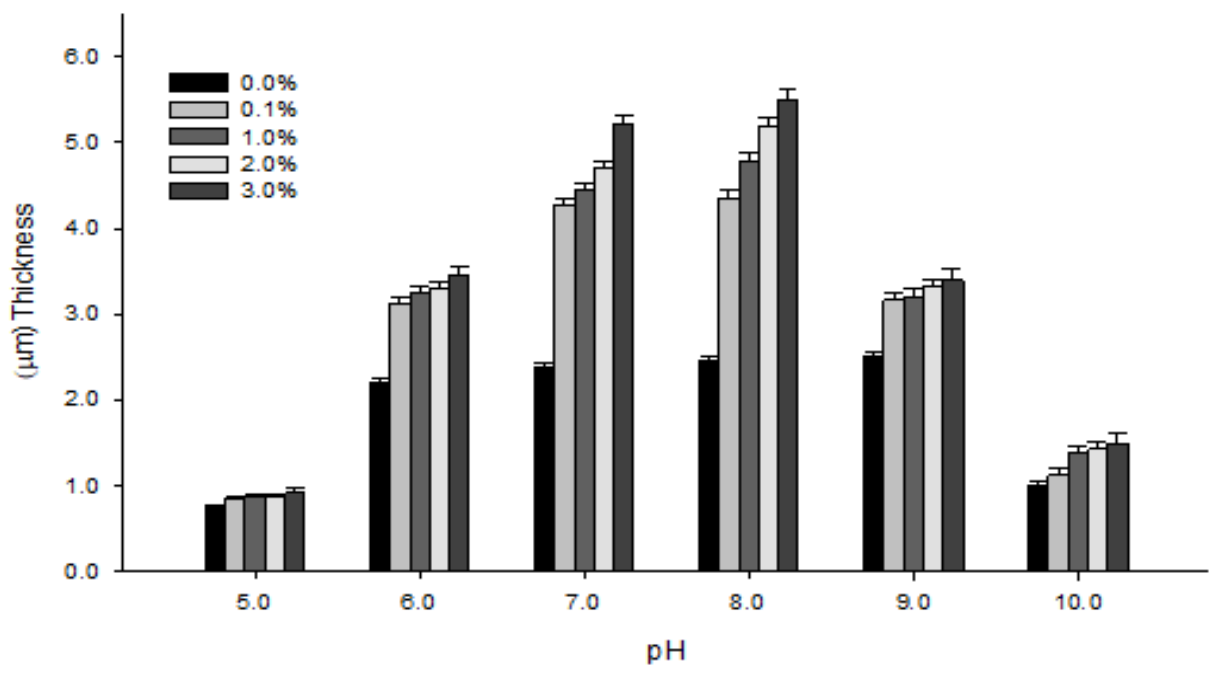

Fig. 3. Changes of the thickness of mucilage.

In this study, we discovered that on C. glomerata, an increase in salinity can accelerate the secretion of EPS, which thickens the extracellular mucilage layer, thereby affecting the attachment of epiphytic algae also.

\subsection{The Influence of Different Salinity on the Level of Polysaccharide and Protein in EPS of C. glomerata}

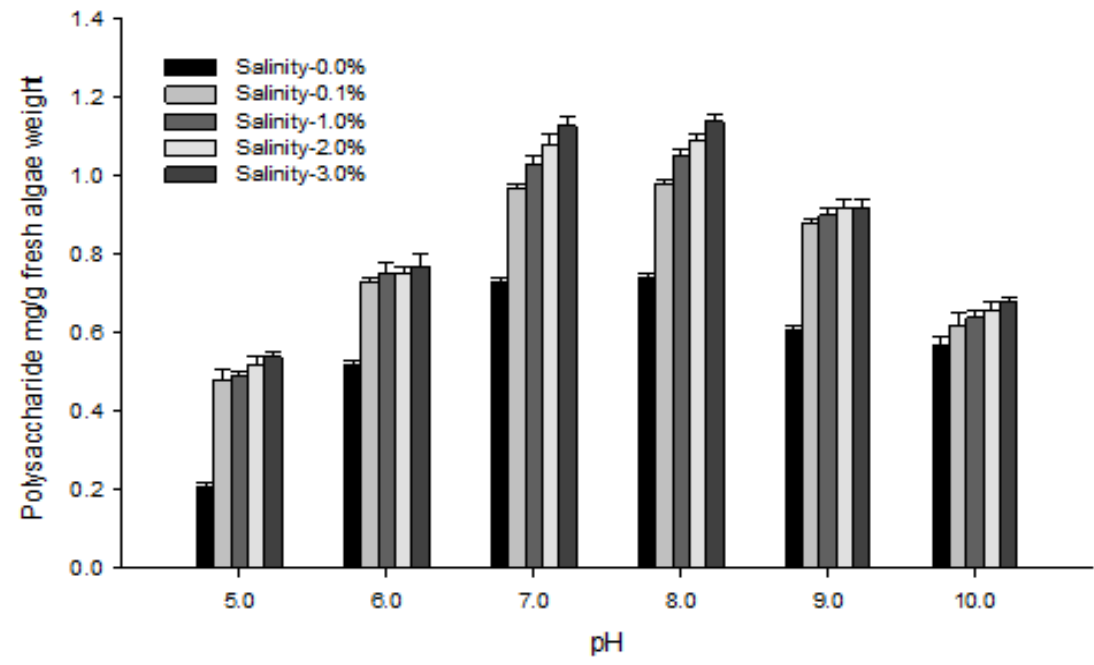

Fig. 4. Polysaccharide level under different culture $\mathrm{pH}$ and salinity. 


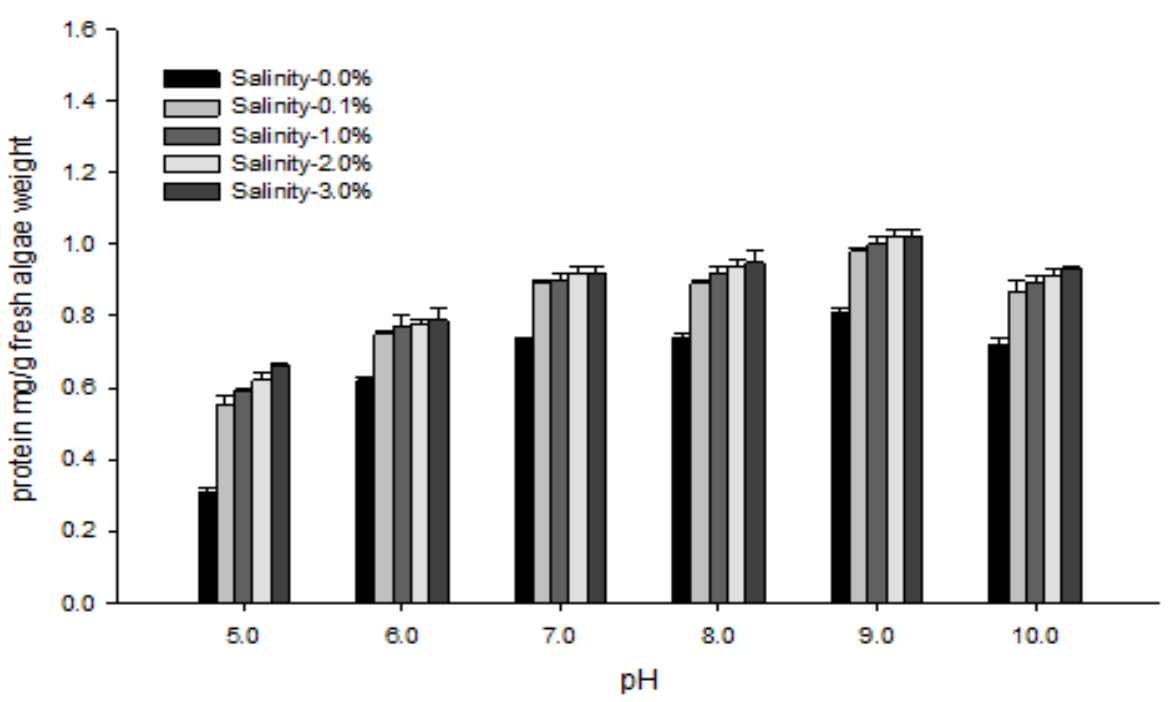

Fig. 5. Protein level under different culture $\mathrm{pH}$ and salinity.

The changes in polysaccharide levels in EPS under different salinities and pH values are shown in Fig. 4. The changes in protein levels in EPS under different salinities are shown in Fig. 5. From previous results, salinity impacts $C$. glomerata protein and polysaccharide.

Therefore, changes in salinity may stimulate algae originally grown in freshwater areas into producing massive amount of EPS. And the thickness of mucilage layer is increased in accordance with the increase in salinity. The salinity-response was significantly affected by $\mathrm{pH}$. Both for protein and polysaccharide, the maximun level was $1.13 \mathrm{mg} \mathrm{g}^{-1}$ fresh algae of protein, $5.18 \mathrm{mg} \mathrm{g}^{-1}$ fresh algae of polysaccharide at $\mathrm{pH} \mathrm{7.0,}$ and the $5.34 \mathrm{mg} \mathrm{g}^{-1}$ fresh algae of protein, $1.14 \mathrm{mg} \mathrm{g}^{-1}$ fresh algae of polysaccharide at $\mathrm{pH}$ 8.0. But the salinity-response for $\mathrm{pH}$ 9.0, 10.0 and $\mathrm{pH}$ 5.0, 6.0 were not significantly different.

By exploring the euryhaline feature of $C$. glomerata, this study discovered that mucilage layer could be massively induced by regulating environmental salinity under favoured $\mathrm{pH}$ range.

\subsection{The Influence of Salinity and pH on the C. glomerata EPS}

To determine the influence of variations in salinity and $\mathrm{pH}$ on the EPS and epiphytes The total EPS content was measured as the sum of polysaccharide and protein Fig. 6 and Table 2 shows the change of the total EPS of $C$. glomerata at different salinities under six different $\mathrm{pH}$ values.

Table 2. EPS and P/S Ratios under Different Culture pH and Salinity

\begin{tabular}{lllllll}
\hline \hline \multirow{2}{*}{ salinity } & \multicolumn{5}{c}{$\mathrm{pH}$} \\
\cline { 2 - 6 } & 5.0 & 6.0 & 7.0 & 8.0 & 9.0 & 10.0 \\
\cline { 2 - 7 } $1(0 \%)$ & $1.17 \pm 0.02 /$ & $2.71 \pm 0.04 /$ & $3.10 \pm 0.05 /$ & $3.18 \pm 0.05 /$ & $3.09 \pm 0.08 /$ & $2.91 \pm 0.05 /$ \\
& $0.22 \pm 0.01^{*}$ & $0.24 \pm 0.01$ & $0.31 \pm 0.01$ & $0.30 \pm 0.01$ & $0.24 \pm 0.01$ & $0.25 \pm 0.01$ \\
$2(3.0 \% 0)$ & $2.25 \pm 0.04 /$ & $3.32 \pm 0.12 /$ & $5.22 \pm 0.12 /$ & $5.31 \pm 0.12 /$ & $3.92 \pm 0.10 /$ & $3.02 \pm 0.10 /$ \\
& $0.27 \pm 0.01$ & $0.28 \pm 0.01$ & $0.23 \pm 0.01$ & $0.23 \pm 0.01$ & $0.29 \pm 0.02$ & $0.26 \pm 0.00$ \\
$3(10.0 \% 0)$ & $2.30 \pm 0.03$ & $3.59 \pm 0.11 /$ & $5.45 \pm 0.12 /$ & $5.80 \pm 0.13 /$ & $4.08 \pm 0.12 /$ & $3.20 \pm 0.12 /$ \\
& $/ 0.27 \pm 0.00$ & $0.27 \pm 0.02$ & $0.23 \pm 0.01$ & $0.22 \pm 0.01$ & $0.29 \pm 0.02$ & $0.25 \pm 0.01$ \\
$4(20.0 \% 0)$ & $2.39 \pm 0.04 /$ & $3.71 \pm 0.08 /$ & $5.75 \pm 0.10 /$ & $6.24 \pm 0.11 /$ & $4.24 \pm 0.13 /$ & $3.27 \pm 0.13 /$ \\
& $0.28 \pm 0.01$ & $0.26 \pm 0.01$ & $0.23 \pm 0.01$ & $0.21 \pm 0.00$ & $0.28 \pm 0.02$ & $0.25 \pm 0.01$ \\
$5(30.0 \% 0)$ & $2.46 \pm 0.02 /$ & $3.82 \pm 0.14 /$ & $6.31 \pm 0.14 /$ & $6.47 \pm 0.10 /$ & $4.32 \pm 0.12$ & $3.35 \pm 0.12 /$ \\
& $0.28 \pm 0.00$ & $0.25 \pm 0.02$ & $0.22 \pm 0.01$ & $0.21 \pm 0.01$ & $/ 0.27 \pm 0.02$ & $0.25 \pm 0.01$ \\
\hline *(EPS / P/S $)$ & & & & & Unit: mg g-1 fresh algae \\
EPS=P+S, P/S: Protien/ Polysaccharide
\end{tabular}




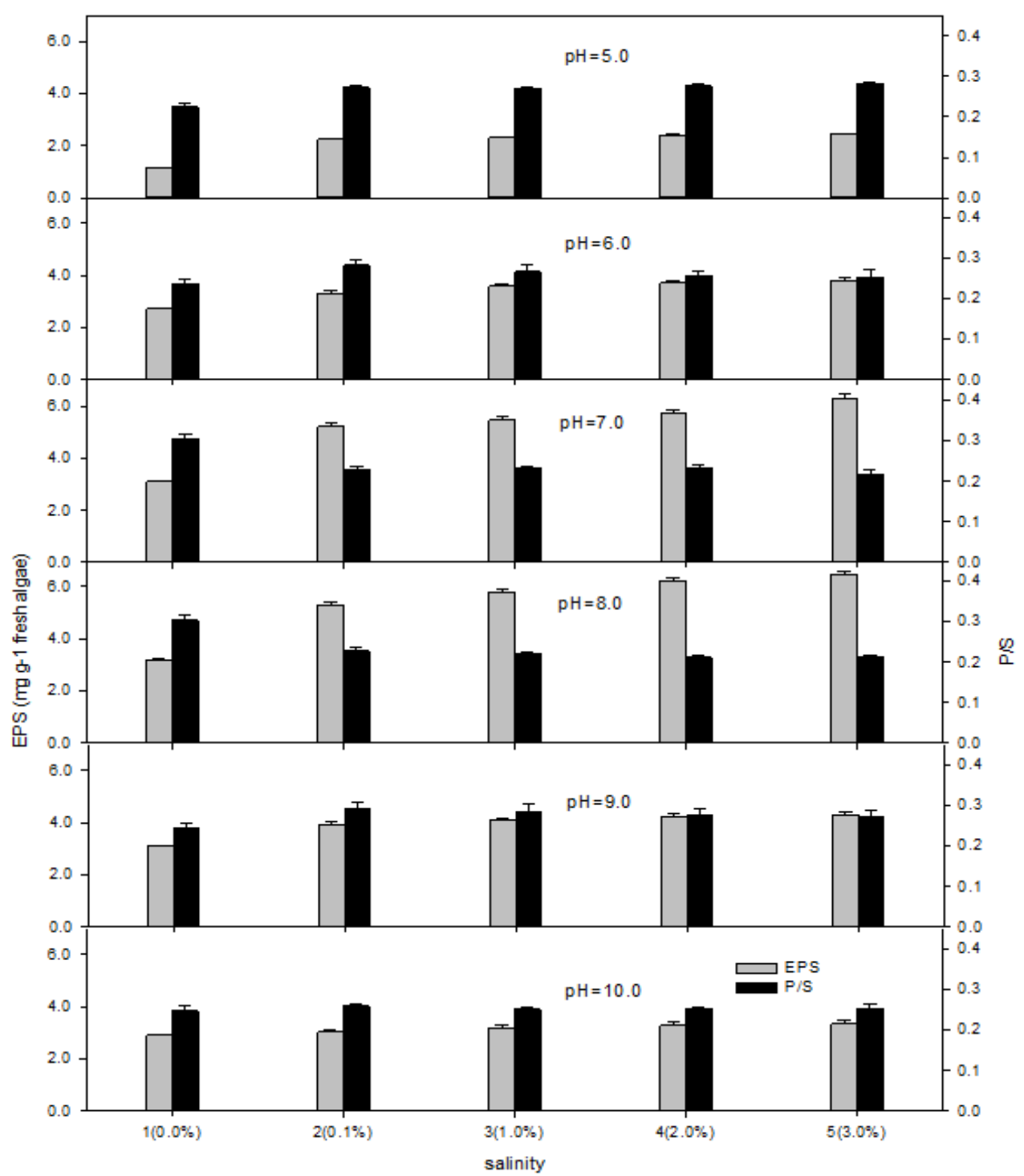

Fig. 6. Variation of EPS and P/S of C. glomerata under different culture salinity and pH.

The total EPS increased from $3.10 \mathrm{mg} \mathrm{g}^{-1}$ fresh algae to $6.31 \mathrm{mg} \mathrm{g}^{-1}$ fresh algae $\mathrm{mg} \mathrm{g}^{-1}$ fresh algae with the increase in the salinity from $0 \%$ to $30 \%$ under pH 7.0. Similarly the total EPS also increased from $3.18 \mathrm{mg}$ $\mathrm{g}^{-1}$ fresh algae to $6.47 \mathrm{mg} \mathrm{g}^{-1}$ fresh algae under $\mathrm{pH} 8.0$ culture condition. The phenomenon of $\mathrm{pH}$ influences the salinity-response effect, which was strongly observed at $\mathrm{pH} 7.0$ and 8.0, but not for $\mathrm{pH} 5.0,6.0$ and pH 9.0, 10.0 culture conditions. Under the $\mathrm{pH} 7.0$ and 8.0 culture conditions, the protein to polysaccharide ratios in EPS decreased from 0.31 to 0.21 with the increase in the salinity from $0 \%$ to $30 \%$. For pH 5.0, 6.0 and $\mathrm{pH} 9.0,10.0$ culture conditions the P/S ratio between 0.24 to 0.29 . Some studies have reported the increase in salinity could cause microoganisms to produce more exopolysaccharide due to the variation of osmotic pressure between microoganisms and the bulk solution [19], [26].

The study discovered that EPS could be massively induce by regulating salinity under favourable $\mathrm{pH}$ condition, and the contents of protein and polysaccharide in EPS can also be controlled using the different salinities of culture condition. And the level of polysaccharide / protein ratio in EPS can also be controlled using the different salinity of habitats when controlling other environmental factors.

\section{Summary}

This study compared the content and the EPS production from the C. glomerata under different culture 
salinity and $\mathrm{pH}$. The results showed that 1) C. glomerata has great development potential for EPS production. 2) under pH7.0 and 8.0, the culture salinity increased the mucilage layer thickness (EPS) increased accordingly. 3) The salinity-respone for EPS was significantly affected by algal favoured $\mathrm{pH}$ range. 4) under $\mathrm{pH} 7.0$ and $\mathrm{pH} 8.0 \mathrm{P} / \mathrm{S}$ between 0.21 to 0.31 , for $\mathrm{pH}$ 5.0, 6.0 and $\mathrm{pH} 9.0$ between 0.24 to 0.29 .5 ) The EPS can be massively induce by regulating salinity under favourable $\mathrm{pH}$ condition, and the contents of protein and polysaccharide in EPS can also be controlled using the different salinities of culture condition.

\section{References}

[1] Mishra, A., \& Jha, B. (2009). Isolation and characterization of extracellular polymeric substances from micro-algae Dunaliella salina under salt stress. Bioresour. Technol., 100(13), 3382-3386.

[2] Mishra, A., Kavita, K., \& Jha, B. (2011). Characterization of extracellular polymeric substances produced by micro-algae Dunaliella salina. Carbohydr. Polym., 83(2), 852-857.

[3] Paniagua-Michel, J. J., Olmos-Soto, J., \& Morales-Guerrero, E. (2013). Algal and microbial exopolysaccharides: New insights as biosurfactants and bioemulsifiers. Adv. Food Nutr. Res., 73, 221-257.

[4] Pignolet, O., Jubeau, S., Vaca-Garcia, C., \& Michaud, P. (2013). Highly valuablemicroalgae: Biochemical and topological aspects. J. Ind. Microbiol. Biotechnol., 40(8), 781-796.

[5] Sheng, G. P., Yu, H. Q., \& Li, X. Y. (2010). Extracellular polymeric substances (EPS) of microbial aggregates in biological wastewater treatmentsystems: A review. Biotechnology Advances, 28(6), 882-894.

[6] Zheng, Y., Xiao, R., \& Roberts, M. (2016). Polymer-enhanced enzymatic microalgal cell disruption for lipid and sugar recovery. Algal Res., 14, 100-108.

[7] Chi, Z., Su, C. D., \& Lu, W. D. (2007). A new exopolysaccharide produced by marine Cyanothece sp. 113. Bioresource Technol., 98(6), 1329-1332.

[8] Xiao, R., \& Zheng, Y. (2016). Overview of microalgal extracellular polymeric substances (EPS) and their applications. Biotechnology Advances, 34(7), 1225-1244.

[9] Tien, C. J., Krivtsov, V., Levado, E., Sigee, D. C., \& White, K. N. (2002). Occurrence of cell-associated mucilage and soluble extracellular polysaccharides in Rostherne Mere and their possible significance. Hydrobiologia, 485(1-3), 245-252.

[10] Chiou, Y. T., Hsieh, M. L., \& Yeh, H. H. (2010). Effect of algal extracellular polymer substances on UF membrane fouling. Desalination, 250(2), 648-652.

[11] Wingender, J., Neu, T. R., \& Flemming, H. C. (2012). Microbial extracellular polymeric substances: Characterization, structure and function. Springer Science \& Business Media.

[12] Xiaomeng, H., Zhiwei, W., Chaowei, Z., \& Wu, Z. (2013). Effect of ultrasonic power density on extracting loosely bound and tightly bound extracellular polymeric substances. Desalinat., 329(15), 35-40.

[13] Huacheng, X., Guanghui, Y., \& Jiang, J. H. (2013). Investigation on extracellular polymeric substances from mucilaginous cyanobacterial blooms in eutrophic freshwater lakes. Chemosphere, 93(1), 75-81.

[14] Zheng, Y., Xiao, R., \& Roberts, M. (2016). Polymer-enhanced enzymaticmicroalgal cell disruption for lipid and sugar recovery. Algal Res., 14, 100-108.

[15] Dodds, W. K., \& Gudder, D. A. (1992). The ecology of Cladophora. Journal of Phycology, 28(4), 415-427.

[16] Ball, R. C., Kevern, N. R., \& Linton, K. J. (1969). The red cedar river report II. Bioecology. Publications of the museum, Michigan State University, biological Series 4, 105-160.

[17] Wen, C. G., Kao, M. M., Chang, S. P., \& Lee, C. S. (2007). A study of macroalgae in headwater of reservoir. Final Report (Project No. EPA-95-G107-02-222), 20-23. Taipei: EPA of R.O.C.

[18] Higgins, S. N., Malkin, S. Y., Howell, E. T., Guildford, S. J., Campbell, L., Hiriart-Baer, V., \& Hecky R. E. 
(2008). An ecological review of Cladophora glomerata (Chlorophyta) in the Laurentian Great Lakes. Journal of Phycology, 44(4), 839-854.

[19] Mishra, A., Mandoli, A., \& Jha, B. (2008). Physiological characterization and stress-induced metabolic responses of Dunaliella salina isolated from salt pan. J. Ind.Microbiol. Biotechnol., 35(10), 1093-1101.

[20] Xu, H. C., Cai, H. Y., Yu, G. H., \& Jiang, H. L. (2013). Insights into extracellular polymeric substances of cyanobacterium Microcystis aeruginosa using fractionation procedure and parallel factor analysis. Water Res., 47(6), 2005-2014.

[21] Matsumoto, T., Yamamura, H., Hayakawa, J., Watanabe, Y., \& Harayama, S. (2014). Influence of extracellular polysaccharides (EPS) produced by two different green unicellular algae on membrane filtration in an algae-based biofuel production process. Water Sci. Technol., 69(9), 1919-1925.

[22] Dubois, M., Gilles, K. A., Hamilton, J. K., Rebers, P. A., \& Smith, F. (1956). Colorimetric method for determination of sugars and related substances. Anal. Chem. 28(3), 350-356.

[23] Bradford, M. M. (1976). A rapid and sensitive method for the quantitation of microgram quantities of protein utilizing the principle of protein-dye binding. Anal. Biochem., 72(1-2), 248-254.

[24] Alasonati, E., \& Slaveykova, V. I. (2012). Effects of extraction methods on the composition and molar mass distributions of exopolymeric substances of the bacterium Sinorhizobium meliloti. Bioresour. Technol., 114, 603-609.

[25] Wang, L. P., Shen, Q. R., Yu, G. H., Ran, W., \& Xu, Y. C. (2012). Fate of biopolymers during rapeseed meal and wheat bran composting as studied by two-dimensional correlation spectroscopy in combination with multiple fluorescence labeling techniques. Bioresour. Technol., 105, 88-94.

[26] Spona, D. T. (2003). Investigation of extracellular polymer substances (EPS) and physicochemical properties of different activated sludge flocs under steady state conditions. Enzyme Microb. Technol., $32(3-4), 375-385$.

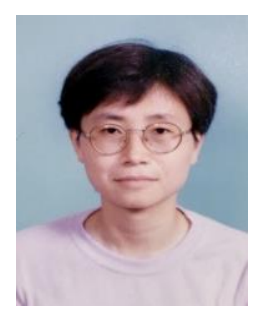

Yi-Chao Lee is an assistant professor at Department of Environment Engineering, Kun Shan University in Taiwan. She was born in Chiayi, Taiwan on November 14, 1966. She obtained a master's degree in civil engineering from National Chiao Tung University in Taiwan. Her main research areas focus on the environmental engineering.

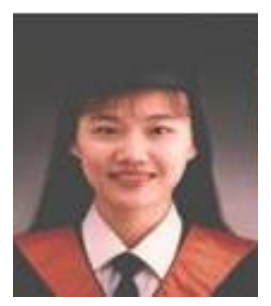

Hwey-Lin Sheu is an associate professor at Department of Environment Engineering, Kun Shan University in Taiwan. She was original born in Nantow, Taiwan on January 3, 1969. She received her Ph.D. degree at National Cheng Kung University in Taiwan. Her main research areas focus on the protection of environment.

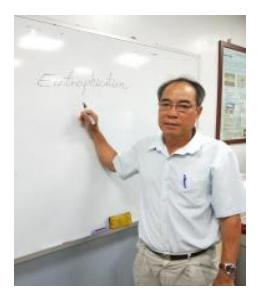

Shui-Ping Chang was born in Taiwan in 1954. He got the B.S. in botany, National Chung Hsing University (Taichung, Taiwan); the M.S. in environmental science, SUNY at Syrcause, New York, U.S.A.; and the Ph.D. of environmental engineering, National Cheng Kung University

His research interests are algae, bioremediation, water treatment. From 1985-1992, he is senior engineer and section chief at EPA in Taiwan. From 1997, he is associate professor, Department of Environment Engineering, Kun Shan University in Taiwan. 